可視化情報 Vol.24 Suppl. No.1（2 $\left.\begin{array}{llll}2 & 0 & 4 & \text { 年 } 7 \text { 月 }\end{array}\right)$

\title{
赤外線画像から熱伝導率の推定
}

河村 憲作 ${ }^{\circ}$, 早野 誠治, 齋藤 兆古 (法政大学大学院)

堀井 清之 (白百合女子大学)

\section{Estimation of Thermal Conductivity from Infrared Images}

Kensaku KAWAMURA, Seiji HAYANO, Yoshifuru SAITO and Kiyoshi HORII

\section{ABSTRACT}

Previously, we have proposed a new methodology, which makes it possible to extract the physical properties from the visualized magnetic domains in ferromagnetic materials. This new approach to the sequential magnetic images is based on the modal analysis solution vector of initial value problems.

In this paper, we apply this approach to the thermal infrared dynamic image in order to extract the physical parameters as well as regularity that dominate the dynamics of thermal distribution.

As a result, it was difficult to extract the physical parameters as well as regularity dominating the dynamics of thermal distribution, because of complex heating and cooling conditions. However, it has been found that only few images are required to recover the precise infrared images by means of the equivalent characteristic values. Furthermore, applying the modal wavelets analysis to the infrared images well visualizes the heating situations.

Keywords: Equivalent Characteristic Value, Thermal diffusion equations, Infrared images

\section{1. 緒 論}

映像情報による判断は，医学などで見られるように， 極めて具体的な現実の状態把握を可能とする。たとえ言 語が異なる民族ですら，映像情報で意志伝達を行えば䛊 解無く伝わる.このように人間の視覚情報処理は全地球 人類共通の強力な知的機能である.

ニュートンは林檎が木から落下する現象を自分の視覚 で観察し, 最終的に現代力学の最も基礎的な体系である ニュートンカ学を集大成した。この意味で視覚情報から 物理的現象の因果関係を把握するため, 人類の視覚機能 では直接観察不可能な現象を可視化する試みがなされて いる．医学での可視化は，X線から始まり核磁気共鳴を 利用した MRI 画像まで実用化されている．工学・物理 学では，電子顕微鏡やX 線結晶構造解析法が発明された 後, 材料中の物理現象に関する因果関係が明らかにされ た。

筆者らは，このような過去の経過とインターネットに よる時間・空間的相違を克服した情報獲得手段の広範な 普及を鑑み，可視化情報から特異点や規則性を計算機の 強力な反復計算能力を用いて抽出する全く新しい学術分 野の開拓を試みている.この学術を我々は「知的可視化 情報処理 (Smart Visualized Information Processing,
Svip と略記)」と呼び, 従来の「可視化情報処理」と区 別している.これは，訓練された人間の視覚情報処理能 力を前提とする従来の可視化情報処理と異なり，計算機 で全ての可視化情報処理，すなわち，特異点抽出や規則 性抽出など，を行うことを前提とするためである.

筆者らは Svip の 1 例として，方向性珪素鋼板の SEM 画像から，結晶性の品質，還流磁区や機械的ストレスを 受けた部分の磁化特性などの規則性抽出を行った，その 結果，習熟した技術者で無くても方向性珪素鎆板の品質 評価を可能とした。

本稿はSvip のッールとして開発された ECV (Equivalent Characteristic Value)法や線形システム行 列の固有ベクトルを利用した MWT(Modal Wavelets Transform)解析法をアルコールランプで局所加熱中の 赤外線動画像一適用し，材料中の熱伝達現象の規則性抽 出を試みる。その結果, 過熱は熱気体の対流や伝達でな され，そして冷却は複雑な冷却空気の対流を喚起する事 が判明し，熱問題の境界条件は単純では無い事を明らか にした，また，MWTは熱伝達の広がりを多重解像度解 析可能とし，アルコールランプの加熱は熱気体の対流に も拘わらず，比較的集中加熱がなされている事を明らか にした。

すなわち，本論文では，双曲線関数の指数值が，初期 
值問題の固有值と対态することを利用した等価固有値法 を用いて熱伝達系の線形性評価について報告する．赤外 線動画が持つ支配方程式の等価固有值を算出し，赤外線 動画像が高圧縮可能であることや，赤外線動画像にモ一 ダル解析法を適用して，熱分布状態の新しい可視化法に ついて報告する。

\section{2. 電気回路と温度の ECV}

2.1 等価固有值 (Equivalent Characteristic Value) ECVは, 信号が双曲線関数の指数部を計算可能な最小 離散化点数 3 点每に計算可能である, 系から与えられる 時間領域の信号を初期值問題の解と仮定して解析するこ とで系の性質, すなわち, 系の特徵量 ECVを抽出する ${ }^{1)}$.

\section{2 電気回路の ECV}

電気抵抗 $\mathrm{R}$ とインダクタンス $\mathrm{L} か ゙$ 直列に接続された電 気回路一直流電圧 $\mathrm{V}$ が印加された場合, 出力電流は Fig. 1 のように時間変化する. Fig. 1 の任意の時点 $n \Delta t$ における電流は式(1)で表現できるから，

$$
i_{n \Delta t}=i_{(n+1) \Delta t}+\left[i_{(n-1) \Delta t}-i_{(n+1) \Delta t}\right] \varepsilon^{-\lambda \Delta t}
$$

$\mathrm{R}-\mathrm{L}$ 直列回路の等価固有值 ECV は式(2)で与えられる.

$$
\lambda=-\frac{1}{\Delta t} \ln \left[\frac{i_{n \Delta t}-i_{(n+1) \Delta t}}{i_{(n-1) \Delta t}-i_{(n+1) \Delta t}}\right]
$$

Fig.1の波形に式(2)を適用して得られる ECVをFig. 2 に示す。明らかに，線形なシステムから得られる ECV は一定值の実数である.

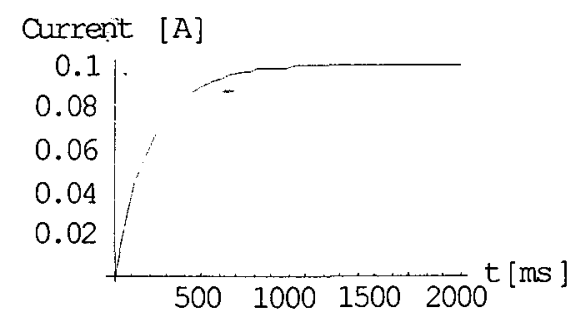

Fig. 1 DC transient Current of a R-L Series Circuit

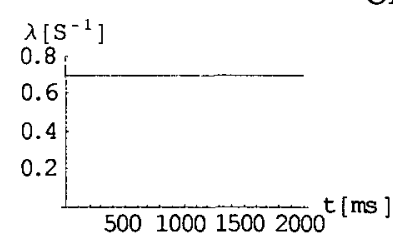

(a) Real Part (b) Imaginary Part

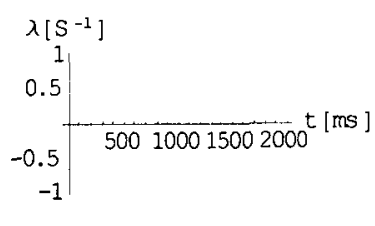

Fig. 2 ECV Evaluated from the Current in Fig. 1 直流電圧入力に対する㤂答から， ECV は正確に計算 される。しかし，交流入力に対する心答信号からは，信 号の時間変化率が小さい部分でノイズが生ずる。この， イズを削减するため，ECV を加算平均処理し，ECV 值 の実数部は入力に依存せずシステムに固有の值を取り， 虚数部は交流入力の角周波数一対梞寸る $\mathrm{ECV}$ 值一収束 することは既に報告した ${ }^{2)}$

\section{3 微小物体における温度}

電気系でない物理系の代表として温度上昇問題を考え る、微小物体の温度方程式は式(3)で表現できる ${ }^{3)}$

$$
\frac{d \theta}{d t}+\frac{\alpha S}{c \rho V}\left(\theta-\theta_{f}\right)-\frac{q_{v}}{c \rho}=0
$$

式(3)より R-L 電気回路同様，任意の時点 $n \Delta t$ における 温度は式(4)で表現できるから，微小温度上昇モデルも等 価固有值が $\mathrm{R} \cdot \mathrm{L}$ 電気回路と同じ様に算定でき,式(5)で与 えられる。

$$
\begin{aligned}
& \theta_{n \Delta t}=\theta_{(n+1) \Delta t}-\left[\theta_{(n+1) \Delta t}-\theta_{(n-1) \Delta t}\right] \varepsilon^{-\lambda \Delta t} \\
& \lambda=-\frac{1}{\Delta t} \ln \left[\frac{\theta_{(n+1)}-\theta_{n \Delta t}}{\theta_{(n+1)}-\theta_{(n-1) \Delta t}}\right]
\end{aligned}
$$

\section{3. 赤外線動画像から固有値算出}

\section{1 偏微分方程式}

実際の温度上昇問題は式(6)に示したような偏微分方 程式で表現される ${ }^{3) 4}$.

$$
\frac{\partial U}{\partial T}=\kappa \frac{\partial^{2} U}{\partial X^{2}}
$$

式(6)は一次元温度上昇問題であり，二次元問題につい て赤外線動画像から固有值を算出することを考える。

\section{2 画像の Poisson 方程式}

画像データは，数值をマトリックス状に配置した画素 (pixel)と呼ばれるもので構成されている，その画素值を スカラポテンシャル $U$ とみなし, 画像の偏微分方程式を 導入する. 静的な画像の支配方程式は式(7)の Poisson 方 程式となる。

$$
\nabla^{2} U=-\sigma
$$

\section{3 画像の Helmholtz 方程式}

動的画像，いわゆるアニメーションに対する支配方程 式は，式(8)のように画像の遷移情報 $t$ に対寸る微分項を 含んだ Helmholtz 方程式となる ${ }^{5) 6)}$.

$$
\nabla^{2} U+\frac{\partial}{\partial t} \varepsilon U=-\sigma
$$

また, 初期値と最終值の画像をそれぞれ $U_{\text {Start }}, U_{\text {Final }}$ とすれば，式(8)の基本解は式(9)となる.

$$
\begin{aligned}
& U(t)=U_{\text {Final }}+\varepsilon^{-A t}\left[U_{\text {Start }}-U_{\text {Final }}\right] \\
& \Lambda=\left[\begin{array}{cccc}
\lambda_{1} & 0 & \cdot & 0 \\
0 & \lambda_{2} & \cdot & 0 \\
\cdot & \cdot & \cdot & \cdot \\
0 & 0 & \cdot & \lambda_{n}
\end{array}\right]
\end{aligned}
$$




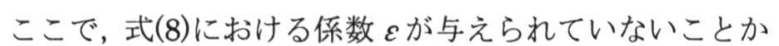
ら式(9)の状態遷移行列 $\varepsilon^{-\Delta t}$ が決定できない. しかしなが ら, 解の画像 $U(t)$ をアニメーション画像の 1 フレームと

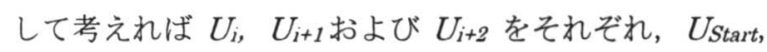
$U(t)$ および $U_{\text {Final }}$ とすれば, 式(11)を用いて行列 $\Lambda$ の要 素が決定できる.

$$
\Lambda=-\frac{1}{\Delta t} \ln \left[\frac{U_{i+1}-U_{i+2}}{U_{i}-U_{i+2}}\right]
$$

式(11)で得られる行列 $\Lambda$ を式(9)に代入すれば, 離散的に 与えられるアニメーションフレームが解析的に生成可能 となる. また, 行列 $\Lambda$ は, 式(8)における係数 $\varepsilon$ に対応す るから, 赤外線動画像に適用すれば, 熱画像から系を支 配するパラメタの抽出が期待できる.

\section{4. 実験・解析}

\section{1 撮影}

$20 \times 30[\mathrm{~cm}]$ の $\mathrm{Al}, \mathrm{Fe}, \mathrm{Cu}$, ステンレスの 4 種類の金 属板で厚さが $0.3,0.5,1.0[\mathrm{~cm}]$ の 3 種類を対象物とし て用意する．暗室内にて Fig. 3 に示寸ようにアルコール ランプを用いて金属板を加熱し, 氷を基準温度として赤 外線カメラで加熱後 90 秒間の撮影を行う. カメラは 1 秒 間に 30 フレームの撮影が可能である.

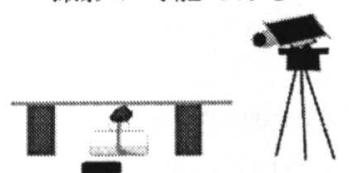

Fig. 3 Infrared Image Measurement System 4.2 金属の違いによる ECV 比較

金属の違いによる ECV の比較を行う. 0.3 [ cm] 厚の金 属板についてFig. 4 に加熱前の画像を示す. 黒い部分が 水である.Fig. 5 は, 加熱後 60 秒後の画像を示してい る. 最も熱伝導率のよい $\mathrm{Cu}, \mathrm{Cu}$ に続く $\mathrm{Al}$ は金属板全 体に高速に熱が均一分布し, 供試赤外線カメラの性能で は熱拡散現象の把握が難しいことがわかる. Fe やステン レスは, 熱分布の差異が大きく, 供試赤外線カメラで熱 拡散現象が把握可能であることがわかる.

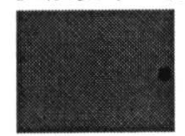

$\mathrm{Fe}$

Fig. 4

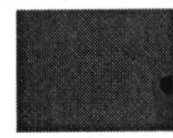

Al

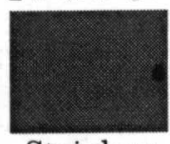

Stainless

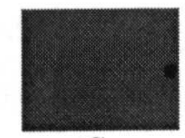

$\mathrm{Cu}$

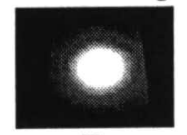

$\mathrm{Fe}$

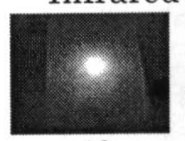

$\mathrm{Al}$

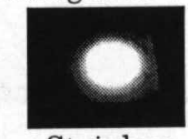

Stainless

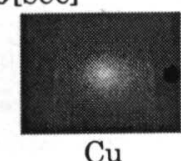

$\mathrm{Cu}$
Fig. 5 Infrared Images at $\mathrm{t}=60$ [sec] 熱拡散速度が比較的遅いことを勘案して，2 秒間隔で 抽出した 3 フレーム画像へ式(11)を適用して ECV を計 算する. Fig. 5 より, ステンレスと Fe は同様な傾向を持 ち, $\mathrm{Al}$ と $\mathrm{Cu}$ は同一傾向にあることから, $\mathrm{Fe}$ と $\mathrm{Cu}$ に 関して得られた ECV をFig. 6 に示す. また, 同図から
加熱後 60 秒経過後の Fe の ECV 分布は明確なコント ラストを有するが, $\mathrm{Cu}$ の $\mathrm{ECV}$ 分布は $\mathrm{Fe}$ ほど明確な コントラストを持たない. よって, 供試赤外線カメラで 熱拡散分布現象が把握可能な Fe について考察する.

Fig. 6 で, ECV 実数部は熱伝達係数分布, 虚数部は 熱入力に対応する.

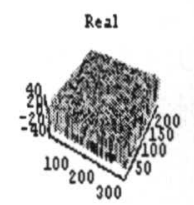

(a) $\mathrm{Fe}(\mathrm{t}=0 \mathrm{~s}, 2 \mathrm{~s}, 4 \mathrm{~s})$

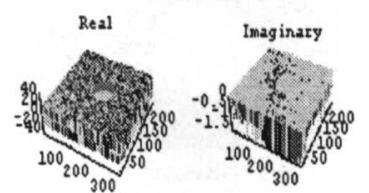

(c) $\mathrm{Fe}(\mathrm{t}=56 \mathrm{~s}, 58 \mathrm{~s}, 60 \mathrm{~s})$

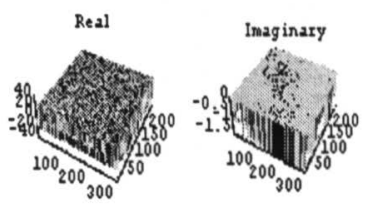

(b) $\mathrm{Cu}(\mathrm{t}=0 \mathrm{~s}, 2 \mathrm{~s}, 4 \mathrm{~s})$

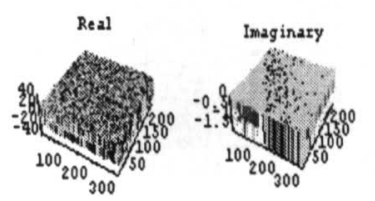

(d) $\mathrm{Cu}(\mathrm{t}=56 \mathrm{~s}, 58 \mathrm{~s}, 60 \mathrm{~s})$
Fig. 6 ECV Distributions Evaluated from the Infrared Images in Fig. 5

\section{3 ECV に対するサンプリング間隔の影響}

$\mathrm{Fe}$ について, 式(11)を用いて 1 秒間隔の 3 フレームと 2 秒間隔の 3 フレーム, それぞれを採用して計算した ECV 分布をFig. 7 に示す. Fig. 7 の結果から 1 秒程度 のサンプリング間隔は ECV 分布に殆ど影響を与えない ことが判る.

これは 2 秒間隔の 3 フレームから求めた行列 $\Lambda$ を式 (9)に適用し，1 秒間隔のフレームが作成可能であること を意味する. 一例として 2 秒間隔の 3 フレームから求め た行列 $\Lambda$ を式(9)へ適用して生成した 1 秒間隔のアニメ ーションフレームと 1 秒間隔の原アニメーションフレ 一ム画像間の相関係数をFig. 8 に示寸. 原画像と生成画 像の相関係数は殆ど 1 であり, ECV 分布を用いればア ニメーション画像の圧縮が可能であることを示している.

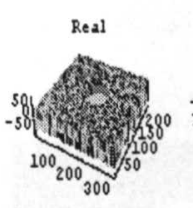

(a) $\mathrm{t}=58 \mathrm{~s}, 59 \mathrm{~s}, 60 \mathrm{~s}$

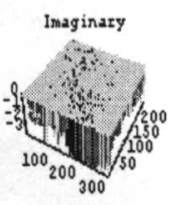

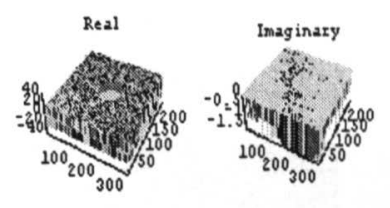

(b) $\mathrm{t}=56 \mathrm{~s}, 58 \mathrm{~s}, 60 \mathrm{~s}$
Fig. $7 \Lambda$ Evaluated from the Different Sampling Periods

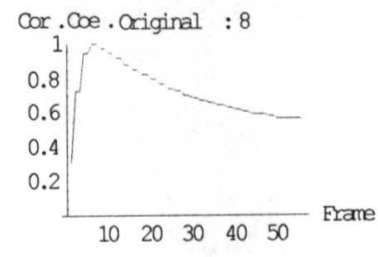

(c) Original 8th Flame

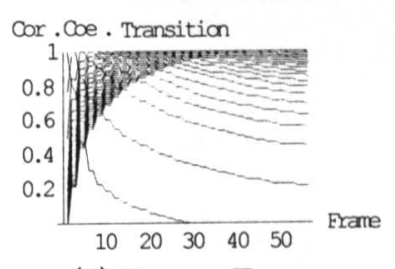

(d) Entire Frame
Fig. 8 Correlation Coefficient between the Generated and Original Animation Flames. 


\section{MWT とベクトル化演算の応用}

\section{1 モーダル解析法を用いた画像分析}

ウェーブレット変換行列とモーダル行列の関係とモー ダル解析法による画像解析の原理は既に報告した ${ }^{677)}$.こ のモーダル解析法を用いた多重解像度解析画像から 3 次元熱分布画像を生成し, Fig. 9 に示寸.

Fig. 9 から金属板, 氷の輪郭が明確に抽出され, 熱画 像を 3 次元で表現することで熱分布が具体的にイメー ジ化されることがわかる。

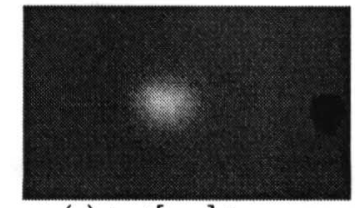

(a) $\mathrm{t}=4$ [sec] image

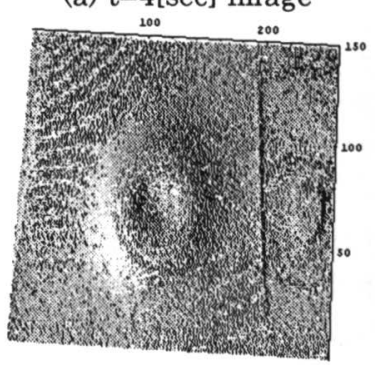

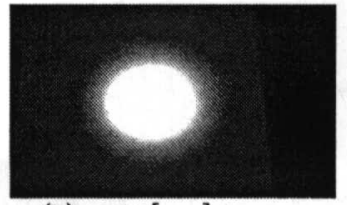

(b) $t=32[\mathrm{sec}]$ image

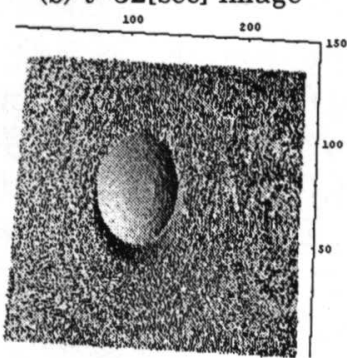

Fig. 9 3D Representation of the Infrared Images

\section{2 ベクトル化解析}

赤外線画像を構成する画素值を，それぞれスカラーと ベクトルポテンシャルの 1 成分と見做し, それぞれへ勾 配演算と回転演算を適用して得られたベクトル化画像を Fig. 10 とFig. 11 にそれぞれ示す.

Fig. 10 より熱勾配がベクトル化され, 熱の広がる方向 が表現可能になることがわかる. また, 赤外線カメラが 対象物を斜めから撮影した為, 多くのベクトルが下方へ 向くのはカメラに接近した部分の熱分布が高感度に撮影 された結果に起因すると考えられる.

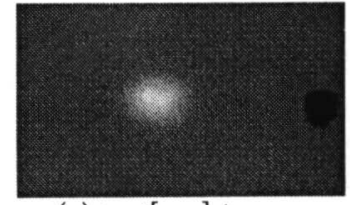

(a) $\mathrm{t}=4[\mathrm{sec}]$ image

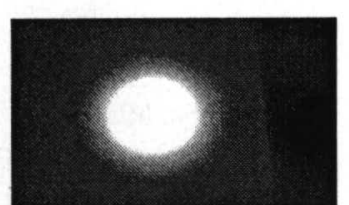

(b) $\mathrm{t}=32[\mathrm{sec}]$ image

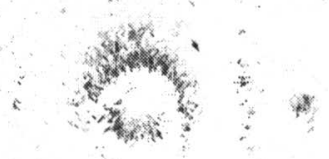

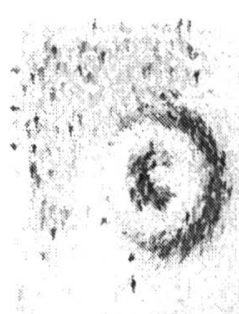
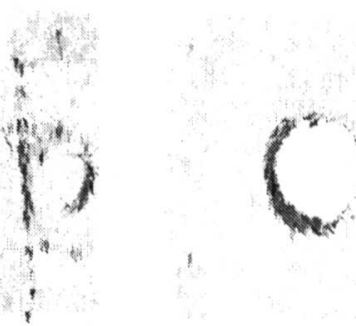

Fig. 11 Rotation Vectors Representation of the Infrared Images

\section{6. まとめ}

本稿はSvip のッールとして開発された ECV (Equivalent Characteristic Value)法や線形システム行 列の固有ベクトルを利用した MWT(Modal Wavelets Transform)解析法をアルコールランプで局所加熱中の 赤外線動画像一適用し, 材料中の熱伝達現象の規則性抽 出を試みた。 その結果, 過熱は熱気体の対流や伝達でな され, そして冷却は複雑な冷却空気の対流を喚起する事 が判明し, 熱問題の境界条件は単純では無い事を明らか にした.

また, MWT は熱伝達の広がりを多重解像度解析可能 とし，アルコールランプの加熱は熱気体の対流にも拘わ らず, 比較的集中加熱がなされている事を明らかにした. すなわち, 本論文では, 双曲線関数の指数值が, 初期 值問題の固有值と対応することを利用した等価固有值法 を用いて熱伝達系の線形性評価について吟味した。赤外 線動画が持つ支配方程式の等価固有值を算出し, 赤外線 動画像が圧縮可能であることや, 赤外線動画像にモーダ ル解析法を適用して, 熱分布状態の新しい可視化法につ いて述べた.

\section{参 考 文 献}

1）茂田幸康, 早野誠治, 斎藤兆古：「磁気センサー信号処理一 概念と一例一」, 電気学会マグネティックス研究会資料, MAG-00-116 (2000).

2）茂田幸康, 早野誠治, 斎藤兆古: 「等価固有值法による磁 気センサー信号処理」, 2002 年度法政大学修士論文 (2003).

3）関信弘:「伝熱工学」, 森下出版 (1988).

4） G・D・スミス:「電算機による偏微分方程式の解法」, サイ エンス社 (1971).

5）遠藤, 早野, 齊藤, 國井：「画像処理の一方法とその動磁 界解析への応用」, 電学論, Vol. 120-A, No. 10 (2000) pp. 913-918.

6) 遠藤久, 斎藤兆古: 「電磁界可視化画像解析法に関寸る研 究」, 2000 年度法政大学修士論文 (2001).

7）斎藤兆古：「知的可視化ツールウェーブレット」。

Fig. 10 Divergent Vectors Representation of the Infrared Images 